\title{
Contribuição ao estudo de índices de uréia e creatinina e urinálise em cães (Canis familiaris) clinicamente saudáveis
}

\author{
Determination of urea and creatinine indices and urinalise of clinically \\ health dogs (Canis familiairs)
}

\author{
Thereza Christina Vasconcelos, ${ }^{*}$ Renato Grechi Pacheco**
}

\begin{abstract}
Resumo
Para análise da função renal são utilizados vários exames que são, até certo ponto, de pouca sensibilidade, daí a necessidade de utilização de testes mais precisos e sensíveis na detecção das alterações no funcionamento dos rins. O presente trabalho de pesquisa teve como objetivo a determinação dos valores de referência para os parâmetros urinários (uréia, creatinina, urinálise), séricos (uréia e creatinina) e das relações uréia urinária/uréia sérica e creatinina urinária/creatinina sérica em cães sadios da raça Pastor Alemão. Utilizaram-se 26 cães machos, com 1 a 6 anos de idade, da raça Pastor Alemão, clinicamente saudáveis e pertencentes à Polícia Militar do Rio de Janeiro. Foram realizadas duas séries de coletas simultâneas de amostras de sangue e urina com intervalo de 15 dias entre elas. Apenas de três animais não foi possível fazer a segunda obtenção de amostras. Determinaram-se os valores da uréia urinária (Uu), uréia sérica (Us), creatinina urinária (Cru), creatinina sérica (Crs) e das relações uréia urinária/uréia sérica (Uu/Us) e creatinina urinária/creatinina sérica (Cru/Crs), que foram, respectivamente: 2,4 a 19,3 (7,04 $\pm 2,945) \mathrm{g} / \mathrm{dl} ; 18 \mathrm{a}$ $74(41,40 \pm 11,26) \mathrm{mg} / \mathrm{dl} ; 91$ a $603(262,63 \pm 112,77) \mathrm{mg} / \mathrm{dl} ; 0,45$ a $1,70(0,92 \pm 0.28) \mathrm{mg} / \mathrm{dl} ; 56,76$ a $348,48(169,86 \pm$ $68,50)$ e 70 a $945(326,27 \pm 193,15)$. O exame de urina (urinálise), em relação ao exame físico, mostrou que a cor variou do amarelo-claro ao amarelo-ouro, o odor foi sui generis, o aspecto variou de transparente a turvo, a consistência foi fluida, a densidade oscilou entre 1.016 a $1.080(1.048 \pm 46)$ e o pH manteve-se entre 5.0 a 8.0 (5.9 \pm 0.9$)$. A maioria das amostras de urina (90\%) apresentou $\mathrm{pH}$ igual ou inferior a 7.0. Por sua vez, ao exame químico foram observadas proteinúria $(20,24 \%)$, bilirrubinúria $(4,08 \%)$ e sangue oculto $(12,24 \%)$. A sedimentoscopia $(400 \mathrm{X})$ revelou a presença de cristalúria (oxalato de cálcio: 4,08\%, fosfato de cálcio: $8,16 \%$, fosfato triplo: $8,16 \%$, uratos amorfos: $6,12 \%$ ); cilindrúria $(4,08 \%)$ (cilindros granulosos: raros a 1 por campo), piúria (100\%) (piócitos: 1 a 20 por campo), hematúria (100\%) (hemácias: 1 a 7 por campo), células descamativas (100\%) (1 a 8 por campo) e espermatúria (48,97\%).
\end{abstract}

Palavras-chave: cão; uréia; creatinina; urinálise.

\section{Introdução}

Atualmente, na rotina laboratorial para análise da função renal, são utilizados vários exames (soro sangüíneo: uréia e creatinina - urina: urinálise - sangue: hemograma) que são, até certo ponto, de pouca sensibilidade, daí a necessidade de utilização de testes mais precisos e sensíveis na deteç̧ão das alterações no funcionamento dos rins. A precocidade na detecção de anomalias na fisiologia renal pode ser a diferença, para o animal, entre a vida e a morte.

A creatinina é uma substância nitrogenada não-protéica formada graças ao metabolismo não enzimático da creatina e fosfocreatina no tecido muscular (Finco e Barsanti, 1982). Os rins são a principal via para excreção da creatinina e como esta atravessa livremente a membrana basal glomerular, sua concentração no filtrado glomerular é similar à do plasma sangüíneo. Embora a creatinina não seja reabsorvida pelos túbulos renais de espécimes caninos e felinos, tem sido identificado um fraco mecanismo secretor tubular proximal em cães normais (O'Connell et al., 1962 ; Swanson e Hakim, 1962). Como a produção de creatinina é constante, a determinação de sua concentração sérica fornece um índice grosseiro da taxa de filtração glomerular. Anormalidades pré-renais, renais e pós-renais que diminuam a taxa de filtração glomerular causam aumento da creatininemia. A hipercreatininemia, devido à lesão renal, não será detectada até que aproximadamente $3 / 4$ ou mais do parênquima de ambos os rins estejam comprometidos (Watson et al., 1981).

A creatininemia não é influenciada pela dieta nem por fatores catabólicos, que, todavia, interferem na formação de uréia, tais como: a febre, a toxemia, as infecções e a administração de certas drogas (Coles, 1984). Os valores normais para a creatinina sérica $(\mathrm{mg} / \mathrm{dl})$ em cães sadios

\footnotetext{
*Professora titular da disciplina de Bioquímica I e II: UNIPLI - Rua Magnólia Brasil 41/ 802 B - Fonseca - Niterói - (21) 6272197.

**Professor adjunto de Patologia Clínica da UFRRJ.
} 
são: 1.0 a 2.0 (Medway et al., 1973); 0.5 a 1.5 (Kaneko, 1980); 1 a $2 \mathrm{mg} / \mathrm{dl}$ (Goldston et al., 1981); menor do que 1.5 (Duncan e Prasse, 1982) e 1.0 a 1.7 (Coles, 1984). Em relação a creatinina urinária de cães normais, os valores citados por KIRK (1988) oscilaram entre 100 a 300 mg/dl, enquanto os referenciados por Jergens et al. (1987) variaram entre $42 \mathrm{a} 416 \mathrm{mg} / \mathrm{dl}$ em animais submetidos a jejum de 12 horas e entre 60 a $324 \mathrm{mg} / \mathrm{dl}$ nos animais alimentados antes da coleta de urina.

A uréia é sintetizada no fígado, representando o principal produto final do catabolismo protéico. Essa substância normalmente não desempenha qualquer função útil no organismo, que não uma possível ação diurética suave, sendo excretada quase inteiramente pelos rins. Os glomérulos renais filtram a uréia do plasma sangüíneo e, sob condições normais, aproximadamente 25 a $40 \%$ da uréia filtrada é reabsorvida na sua passagem pelos túbulos renais. Velocidades de fluxo urinário maiores que o normal diminuem a reabsorção tubular, enquanto que baixas velocidades aumentam a sua reabsorção (Coles, 1984).

Os valores de normalidade para a uréia sérica $(\mathrm{mg} / \mathrm{dl})$ em cães saudáveis, referenciados na literatura por Duncan e Prasse (1982), Smith et al. (1985), Ettinger e Feldman (1995) foram, respectivamente de: 11 a 60,10 a 25 e 8 a 25. Segundo KIRK (1988), a uréia urinária de cães sadios oscila entre 1 a $2,5 \mathrm{~g} / \mathrm{dl}$ (1000 a $2.500 \mathrm{mg} / \mathrm{dl})$.

A utilização de índices urinários (creatinina urinária/ creatinina sérica: Cru/Crs - uréia urinária / uréia sérica: Uu/Us), apesar de não serem testes definitivos para análise da função renal, são indicadores preliminares valiosos na diferenciação entre a hiperazotemia pré-renal aguda e a necrose tubular aguda (Grossman et al., 1982). A relação $\mathrm{Cru} / \mathrm{Crs}$ foi objeto de estudo de vários autores. Sendo assim, Edwards et al. (1989) citaram como normais para eqüinos adultos, os valores de 22,87 a 655,80 (199,84 \pm $111,15)$, enquanto Duncan et al. (1994) comentaram que, na diferenciação entre hiperazotemia pré-renal e renal os valores foram, respectivamente, maiores de 50 e inferiores a 37. Ettinger e Feldman (1995), em cães, referenciaram para a insuficiência renal valores abaixo de 10 e, para a hiperazotemia pré-renal, acima de 20. Por sua vez, Grossman et al. (1982), em suas pesquisas com eqüinos, verificaram que a Cru/Crs nos animais com hiperazotemia renal oscilou entre 2,6 a 37,0 e nos casos de hiperazotemia pré-renal entre 51,2 a 241,5. Em relação a Uu/Us, Duncan et al. (1994), citaram que nos casos de hiperazotemia renal há diminuição dessa relação. Grossman et al. (1982), comentaram que em casos de hiperazotemia renal os valores foram de 2,1 a 14,3 e, na ocorrência de hiperazotemia pré-renal, oscilaram entre 15,2 a 43,7. Não foram encontradas referências de valores de normalidade, em cães, para as relações acima citadas.

Em relação ao exame de urina de cães sadios - urinálise, a literatura referencia para a sua avaliação física os seguintes resultados: odor (sui generis), consistência (flui- da) e aspecto (de transparente a turvo) (Chew e DiBartola, 1986; Bush, 1991; Meyer et al., 1992 ; Willard et al., 1994 ; Osborne e Finco, 1995). A reação $(\mathrm{pH})$, segundo Bush (1991), Osborne e Finco (1995), varia de 4.5 a 8.5, comentando o primeiro autor ser impossível valores além desses limites e citando como mais freqüente o intervalo entre 5.5 a 7.0. Para outros autores, os valores de $\mathrm{pH}$ referenciados são: 6.0 a 7.0 (Coles, 1984); 5.0 a 7.5 (Chew e DiBartola, 1986); $6.1 \pm 0.3$ (O'Brien et al., 1993); 5.5 a 7.0 (Willard et al., 1994) e 5.5 a 7.5 (Navarro-Garcia, 1996). A cor da urina, segundo diferentes autores, varia do amarelo-pálido ao amarelo-âmbar (Chew e DiBartola, 1986; Matos e Matos, 1988; Bush, 1991; Willard et al., 1994 ; Osborne e Finco, 1995), ou de amarelo-pálido a amarelo-escuro (Coles, 1984 e Meyer et al., 1992) e de amarelo-citrino ao amarelo-âmbar (Navarro-Garcia, 1996). No tocante à densidade, citaramse valores colocados entre 1.015 a 1.045 (Coles, 1984 ; Bush, 1991); 1.015 a 1.040 (Willard et al., 1994) e 1.015 a 1.050 (Matos e Matos, 1988). Osborne e Finco (1995) consideram como limites extremos os valores de 1.001 a 1.065, comentando ainda que o intervalo da densidade mais freqüentemente estaria entre 1.015 a 1.045.

O exame químico, por sua vez, segundo os autores considerados, apresentava resultado negativo para a presença de glicose, corpos cetônicos, sais biliares, urobilinogênio (se a pesquisa desse parâmetro não for feita logo após a coleta), nitrito e sangue (Sodikoff, 1981 ; Duncan e Prasse, 1982 ; Coles, 1984 ; Chew e DiBartola, 1986 ; Matos e Matos, 1988 ; Bush, 1991; Meyer et al., 1992 ; O'Brien et al., 1993 ; Duncan et al., 1994 ; Willard et al., 1994 ; Ling, 1995 ; Osborne e Finco, 1995 ; Navarro-Garcia, 1996). Em relação à bilirrubina, Sodikoff (1981), Matos e Matos (1988) e Meyer et al. (1992) citaram que esse pigmento biliar poderia ser encontrado em pequena quantidade (traços) em cães normais, havendo pesquisadores como Duncan e Prasse (1982), Chew e DiBartola (1986) que destacaram que a bilirrubinúria (traços) seria mais freqüente entre os cães machos. Segundo Bush (1991) e Navarro-Garcia (1996), a presença de bilirrubina na urina (até 1+) é normal em 20\% dos cães sadios, especialmente quando a densidade é igual ou maior do que 1.020 (Willard et al., 1994) ou 1.040 (Osborne e Finco, 1995). No entender de Coles (1984), a bilirrubinúria estaria presente em 20 a $60 \%$ dos cães normais, devido ao baixo limiar renal desses animais para a bilirrubina conjugada. A presença de proteína na urina não é normal (Duncan e Prasse, 1982 ; Coles, 1984 ; Matos e Matos, 1988; Osborne e Finco, 1995), sendo que alguns cães sadios apresentariam proteinúria transitória (traços), principalmente em amostras concentradas (Ducan et al., 1994) e naquelas coletadas pela manhã (Navarro-Garcia, 1996). Em situações de estresse (Chew e DiBartola, 1986 ; Matos e Matos, 1988 ; Navarro-Garcia, 1996) e exercícios intensos (Coles, 1984; Chew e DiBartola, 1986 ; Matos e Matos, 1988 ; Meyer et al., 1992 ; Willard et al., 1994 ; Navarro-Garcia, 1996) uma discreta proteinúria poderia ser encontrada, sendo um resultado do aumento da permeabilidade glomerular resultan- 
te de congestão capilar nessa região (Matos e Matos, 1988). O aparecimento de urina alcalina em cães normais poderia ocasionar resultados falso-positivos para proteinúria (Coles, 1984 ; Chew e DiBartola, 1986 ; Bush, 1991 ; Meyer et al., 1992 ; Duncan et al., 1994 ; Willard et al., 1994 ; Osborne e Finco, 1995).

O exame microscópico do sedimento urinário de cães normais poderia apresentar células epiteliais oriundas do urotélio, bactérias provenientes da flora uretral, cristais próprios de urina ácida e alcalina e espermatúria discreta (Coles, 1984 ; Chew e DiBartola, 1986 ; Bush, 1991 ; Osborne e Finco, 1995). Somente ocasionais eritrócitos estariam presentes na urina de cães sadios (Sodikoff, 1981; Chew e DiBartola, 1986 ; Bush, 1991) e, segundo Chew e Dibartola (1986) essa hematúria poderia ser devido aos exercícios intensos. Os resultados da quantificação dos eritrócitos presentes em amostras normais de urina canina seriam semelhantes, pois Meyer et al. (1992), Ling (1995) e Osborne e Finco (1995) citaram, respectivamente, os valores de 0 a 3 , menos de 5 e 0 a 5 por campo de grande aumento (CGA). Navarro-Garcia (1996) comentou que o número de eritrócitos por campo de pequeno aumento (CPA), na urina de cães normais poderia variar, dependendo do método de coleta: micção normal (até 7/CPA), cateterismo (até 5/CPA) e cistocentese (até $3 / C P A$ ).

0

Apenas poucos leucócitos estariam fisiologicamente presentes na urina de cães saudáveis (Sodikoff, 1981 ; Coles, 1984 ; Chew e DiBartola, 1986 ; Bush, 1991 ; Ling, 1995 ; Navarro-Garcia, 1996). Normalmente cães sadios apresentam 0 a 5 leucócitos por CGA (Osborne e Finco, 1995). Navarro-Garcia (1996) comentou ainda, que o exercício intenso poderia ser a causa de uma pequena e temporária leucocitúria. A quantidade de leucócitos na urina de cães normais poderia variar com o método de coleta utilizado, pois Chew e DiBartola (1986) citaram os seguintes valores por CGA: micção voluntária (0 a 8), cateterização (0 a 5) e cistocentese (0 a 3). No entanto Meyer et al. (1992) citaram como normais para cães sadios valores numéricos de leucócitos de 0 a 3 por CGA, quando a amostra de urina era coletada por cistocentese. Ling (1995) comentou que na micção voluntária, os leucócitos encontrados na urina poderiam ser oriundos da vagina, vulva, prepúcio ou glande. Processos patológicos também poderiam influenciar a leucocitúria e, segundo Duncan e Prasse (1982), mais de 5 a 8 leucócitos por CGA indicariam inflamação de vias urinárias, enquanto que para Matos e Matos (1988) esse limite situava-se em mais de 5 leucócitos por CGA. No entender de Ling (1995), a presença de leucócitos na urina de cães seria sugestiva de infeção urinária e deveria ser analisada considerando-se o método de coleta, pois os valores difeririam na cistocentese (mais de 3 leucócitos por CGA seria indício de processo inflamatório de vias urinárias), na cateterização (mais de 8 leucócitos por CGA sugeriria processo inflamatório) e micção voluntária (mais de 10 leucócitos por CGA indicaria possibilidade de processo inflamatório).
Normalmente, na urina de cães sadios, não existiriam cilindros mas, segundo Chew e DiBartola (1986), a cilindrúria poderia ser normal nesses animais quando representada por cilindros hialinos ( 0 a 2 por $C P A$ ) e cilindros granulosos ( 0 a 1 por $C P A)$. Outros autores, porém, apresentaram valores diferentes dos citados anteriormente: Bush (1991) (cilindros hialinos - 1 a 2 por CPA e cilindros granulosos 1 por CPA); Meyer et al. (1992) (cilindros hialinos - igual ou inferior a 2 por CPA e cilindros granulosos - igual ou inferior a 1 por CPA); Willard et al. (1994) (cilindros granulosos - 0 a 2 por CGA); Ling (1995) (cilindros hialinos e granulosos - 1 a 2 por CGA) e Osborne e Finco (1995) (cilindros hialinos - ocasionais por CPA). Todavia, Coles (1984) considerou que a linha divisória entre o normal e o anormal em cães se situaria entre 2 a 4 cilindros por CPA, enquanto que Navarro-Garcia (1996), afirmou que os cilindros hialinos poderiam surgir em cães sadios submetidos a exercícios intensos.

O presente trabalho teve como objetivo a determinação dos valores de referência para os parâmetros urinários (uréia, creatinina,urinálise), séricos (uréia e creatinina) e das relações uréia urinária/uréia sérica e creatinina urinária/ creatinina sérica, em cães sadios da raça Pastor Alemão.

\section{Material e métodos}

Foram utilizados 26 cães machos, com idade entre 1 e 6 anos, da raça Pastor Alemão, clinicamente saudáveis, de propriedade da Polícia Militar do Estado do Rio de Janeiro e que se alimentavam com ração comercial ${ }^{1}$ uma vez ao dia. Havia livre acesso à água. Todos os animais receberam o mesmo tipo de manejo, que consistia em seis meses de adestramento e posterior patrulhamento das ruas.

Após um jejum de 12 horas, foram coletadas amostras de sangue em sistema Vacutainer ${ }^{2}$ sem anticoagulante. Simultaneamente à coleta de sangue eram coletadas amostras de urina com sonda flexível ${ }^{3}$ número 4 . Foram realizadas duas séries de coletas de amostras, com intervalo de 15 dias entre uma e outra. As amostras de sangue sem anticoagulante destinaram-se à obtenção de soro para as dosagens de creatinina e uréia. As amostras de urina foram divididas em duas alícotas: uma destinou-se à realização da urinálise $e$ sedimentoscopia, e a outra, á determinação dos valores de creatinina e uréia. A determinação dos parâmetros bioquímicos séricos e urinários foi realizada com a utilização de kit's comerciais ${ }^{4}$ (creatinina: método de picrato alcalino; uréia: método do diacetil modificado) e a leitura realizada por

\footnotetext{
${ }^{1}$ Pedigree Champ, Éffem Produtos Alimentícios, Rio Grande do Sul, Brasil.

2 Becton Dickinson Vacuteiner Systems, New Jersey, Estados Unidos da América do Norte.

${ }^{3}$ Mark Med Indústria e Comércio Ltda, São Paulo, Brasil.

${ }^{4}$ Labtest, Belo Horizonte, Brasil.
} 
espectrofotometria ${ }^{5}$, a urinálise foi realizada com tiras reativas próprias ${ }^{6}$ e a densidade determinada por refratometria ${ }^{7}$ a sedimentoscopia seguiu a técnica descrita por Coles (1984). A determinação dos valores das relações creatinina urinária/creatinina sérica e uréia urinária/ uréia sérica foi feita através de cálculo matemático.

As amostras de urina foram centrifugadas, o sobrenadante urinário e soro sangüíneo foram congelados até o momento da determinação dos valores de creatinina e uréia, enquanto as destinadas a urinálise foram avaliadas logo após a coleta. Apenas em três animais não foi possível realizar a segunda série de coletas de amostras de urina e sangue, perfazendo um total de 49 amostras. Foram determinados os valores mínimos, máximos, média e o desvio padrão, seguindo recomendações de Vieira (1989).

\section{Resultados}

As concentrações séricas de creatinina e uréia oscilaram respectivamente entre 0.45 e $1.70(0.92 \pm 0.28)$ e entre $18 \mathrm{e}$ $74(41,40 \pm 11,26) \mathrm{mg} / \mathrm{dl}$. Em relação à concentração urinária, os valores apresentaram variação entre 91 e 603 (262,63 \pm $112,77) \mathrm{mg} / \mathrm{dl}$ para creatinina e entre 2,40 e 19,30 (7,04 \pm $2,945) \mathrm{g} / \mathrm{dl}$ para a taxa de uréia. A relação creatinina urinária/ creatinina sérica variou entre 70 e $945(326,27 \pm 193,15)$, enquanto que a relação uréia urinária/uréia sérica oscilou entre 56,76 e $348,48(169,86 \pm 68,50)$.

O exame de urina (urinálise), em relação ao exame físico, os resultados que demostraram que a cor variou do amareloclaro ao amarelo-ouro, o odor foi sui generis, o aspecto oscilou entre o transparente e o turvo, a consistência foi fluida, a densidade mostrou valores entre 1.016 e $1.080(1.040 \pm 46) \mathrm{e}$ o $\mathrm{pH}$ manteve-se entre 5.0 e $8.0(5.9 \pm 0.9)$. A maioria das amostras de urina (90\%) apresentou $\mathrm{pH}$ igual ou inferior a 7.0. O exame químico da urina não revelou presença de glicose, nitrito, urobilinogênio e corpos cetônicos, mas foram observadas proteinúria $(20,24 \%)$, bilirrubinúria $(4,08 \%)$ e sangue oculto (12,24\%). A sedimentoscopia (400 X) revelou a presença de cristalúria (oxalato de cálcio: $4,08 \%$, fosfato de cálcio: $8,16 \%$, fosfato triplo: $8,16 \%$, uratos amorfos: $6,12 \%$ ); cilindrúria $(4,08 \%)$ (cilindros granulosos: raros a 1 por campo), piúria (100\%) (piócitos: 1 a 20 por campo), hematúria (1.00\%) (hemácias: 1 a 7 por campo), células descamativas (100\%) (1 a 8 por campo) e espermatúria (48,97\%).

\section{Discussão}

Em relação a creatinina sérica, os valores citados por Kaneko (1980) (0,5 a 1,5 mg/dl) e Duncan e Prasse (1982) (menor do que $1,5 \mathrm{mg} / \mathrm{dl}$ ) foram semelhantes aos desta pesquisa $(0,45$ a $1,70 \mathrm{mg} / \mathrm{dl})$, enquanto que os limites inferiores e superiores referenciados por Medway et al. (1973)

\footnotetext{
${ }^{5}$ Espectrofotômetro SPEC 20 D, São Paulo, Brasil.

${ }^{6}$ Combur-9-test, Boehringer Mannheim, Portugal.

${ }^{7}$ Refratômetro A $300 \mathrm{CL}$, Tóquio, Japão.
}

e Goldston et al. (1981) (1,0 a 2,0 mg/dl) foram superiores. Por sua vez, a citação de Coles (1984) (1,0 a 1,7 mg/dl) apresentou limite inferior maior e superior coincidente. Os valores dos limites inferiores e superiores da creatinina urinária citados por Jergens et al. (1987) (42 a $416 \mathrm{mg} / \mathrm{dl}$ - com jejum e 60 a $324 \mathrm{mg} / \mathrm{dl}$ - sem jejum) foram menores do que os encontrados neste experimento ( 91 a 603 $\mathrm{mg} / \mathrm{dl})$, enquanto que em relação aos referenciados por Kirk (1988) (100 a 300 mg/dl) o limite inferior foi menor e o superior maior. As diferenças entre a creatinina sérica e urinária da referida literatura e desta pesquisa devem ser creditadas à metodologia laboratorial utilizada e às características fisiológicas renais individuas dos cães.

Os limites inferiores e superiores da uréia sérica citados por Duncan e Prasse (1982) (11 a $60 \mathrm{mg} / \mathrm{dl}$ ), Smith et al. (1985) (10 a 25 mg/dl) e Ettinger e Feldman (1995) (8 a 25 $\mathrm{mg} / \mathrm{dl}$ ) foram inferiores aos da presente pesquisa (18 a 74 $\mathrm{mg} / \mathrm{dl})$. O mesmo ocorreu em relação à uréia urinária quando compararam-se os valores de Kirk (1988) (1,0 a 2,5 g/ dl) com os deste experimento $(2,4 \mathrm{a} 19,3 \mathrm{~g} / \mathrm{dl})$. O tipo de alimentação, a metodologia laboratorial empregada e as características fisiológicas renais individuais (velocidade de fluxo do fluido tubular, especialmente em relação à uréia urinária) dos cães foram os principais motivos dessas diferenças.

No tocante à relação creatinina urinária/creatinina sérica, verificou-se que os valores citados por Edwards et al. (1989) - $(22,87$ a 65,80$)$ - apresentaram limite inferior e superior menores do que os da presente pesquisa (70 a 945), provavelmente por se tratar de espécies diferentes. As diferenças entre os valores devem-se principalmente às características fisiológicas individuais dos animais utilizados nas pesquisas referenciadas.

Em relação ao exame físico do EAS, os resultados encontrados para odor, aspecto e consistência, coincidiram com os referenciados por Chew e DiBartola (1986), Matos e Matos (1988), Willard et al. (1994). Por sua vez, a variação encontrada na coloração (amarelo claro a amareloouro) não coincidiu com as citações de Coles (1984), Chew e DiBartola (1986), Matos e Matos (1988) Bush (1991), Meyer et al. (1992), Willard et al. (1994), Osborne e Finco (1995), Navarro-Garcia (1996), provavelmente, devido as variações metabólicas na produção de pigmentos urinários e na quantidade de água ingerida pelos animais. No tocante à densidade urinária, os valores encontrados (1.016 a 1.080) foram semelhantes aos da literatura citada em relação aos limites inferiores e maiores quando comparados os limites superiores, acreditando-se que tal fato deva-se à influência do manejo e atividade dos animais, bem como da maior temperatura ambiente da cidade do Rio de Janeiro. A reação da urina coincidiu com os referenciados por Coles (1984), Chew e DiBartola (1986), Bush (1991), O'Brien et al. (1993), Willard et al. (1994), Osborne e Finco (1995), Navarro-Garcia (1996). 
No exame químico, o resultado negativo para pesquisa de nitrito, glicose e corpos cetônicos foi coincidente com as citações de Sodikoff (1981), Duncan e Prasse (1982), Coles (1984), Matos e Matos (1988), Bush (1991), Meyer et al. (1992), O'Brien et al. (1993), Duncan et al. (1994), Willard et al. (1994), Ling (1995), Osborne e Finco (1995) e NavarroGarcia (1996). A bilirrubinúria (traços) foi considerada normal, conforme citação de Sodikoff (1981), Duncan e Prasse (1982), Matos e Matos (1988) e Meyer et al. (1992). O percentual de bilirrubina na urina encontrado na presente pesquisa foi inferior ao descrito por Coles (1984), Bush (1991), Willard et al. (1994), Osborne e Finco (1995) e Navarro-Garcia (1996). Por sua vez, a proteinúria encontrada nas amostras pesquisadas provavelmente deveu-se ao estresse (Chew e DiBartola, 1986 ; Matos e Matos, 1988 ; Navarro-Garcia 1996) e os exercícios físicos (Coles 1984 ; Matos e Matos 1988 ; Meyer et al., 1992 ; Willard et al., 1994 ; Navarro-Garcia 1996) a que os cães da Polícia Militar são submetidos diariamente, o que leva a uma congestão capilar glomerular com aumento da filtração de proteínas nos glomérulos renais (Matos e Matos, 1988). Apenas uma amostra com $\mathrm{pH}$ alcalino apresentou proteinúria, podendo se tratar de um resultado falso-positivo, o que está em concordância com as citações de Coles (1984), Chew e DiBartola (1986), Bush (1991), Meyer et al., (1992), Duncan et al. (1994), Willard et al., (1994), Osborne e Finco (1995).

Com base nas informações citadas por Coles (1984), Chew e DiBartola (1986), Bush (1991) e Osborne e Finco (1995), não foram encontradas alterações em relação a cristais, bactérias, células descamativas e espermatozóides. A espermatúria pode ter contribuído para a proteinúria (traços) encontrada em algumas amostras. De acordo com a literatura citada, somente ocasionais eritrócitos são normais na urina de cães sadios e, por isso, a hematúria encontrada em $100 \%$ das amostras desta pesquisa pode ter sido devido aos exercícios físicos conforme citam Chew e DiBartola (1986). O número de eritrócitos encontrados por campo de grande aumento (1 a 7) encontram-se em concordância com os citados por Meyer et al. (1992), Ling
(1995), Osborne e Finco (1995). A intensidade da hematúria encontrada neste experimento, onde a urina foi coletada por cateterismo, e próxima da referenciada por NavarroGarcia (1996) em campo de pequeno aumento com o mesmo método de coleta. A leucocitúria encontrada em $100 \%$ das amostras apresentou intensidade ( 1 a 20 piócitos por campo de grande aumento) maior do que a citada por Chew e DiBartola (1986), Meyer et al. (1992) e Osborne e Finco (1995) em cães normais e, por Duncan e Prasse (1982), Matos e Matos (1988), Ling (1995) em cães com inflamação das vias urinárias. Essa intensa leucocitúria, observada nos cães deste experimento, deve ter sido conseqüência de intenso exercício físico conforme citação de Navarro-Garcia (1996), pois não foi detectada nenhuma anormalidade nos animais. Em relação à cilindrúria, observou-se que a quantidade detectada (raros a 1 cilindro granuloso por campo de grande aumento) foi considerada normal, com base nas citações de Coles (1984), Chew e DiBartola (1986), Bush (1991), Meyer et al. (1992), Willard et al. (1994), Ling (1995).

\section{Conclusões}

Os valores normais de creatinina e uréia urinários, para cães pastores alemães de propriedade da Polícia Militar do Rio de Janeiro, variaram respectivamente entre $91 \mathrm{e}$ $603(262.63 \pm 112,77) \mathrm{mg} / \mathrm{dl}$ e 2,40 a 19,30 $(7,04 \pm 2,945)$ $\mathrm{g} / \mathrm{dl}$, e a relação creatinina urinária/creatinina sérica variou entre 70 e 945 (326.27 \pm 193.15$)$, enquanto que a relação uréia urinária/uréia sérica oscilou entre 56.76 e 348.48 (169.86 \pm 68.50$)$.

As concentrações séricas de uréia e creatinina, bem como - EAS, apresentaram concordância com os autores pesquisados.

A partir deste trabalho observou-se a necessidade de maiores estudos, principalmente com animais apresentando patologias, para melhores esclarecimentos sobre a importância e aplicabilidade dos índices urinários como subsídio para diferenciação de azotemia pré-renal e renal.

\section{Abstract}

For analysis of the renal function they are used several exams that are even certain point of little sensibility, then the need of use of more necessary and sensitive tests in the detection of the alterations in the operation of the kidneys. The present research work had as objective the determination of the reference values for the urinary parameters (urea, creatinine, urinalysis), serum (urea and creatinine) and of the relationships urine urea/serum urea and urine creatinine/ serum creatinine, in healthy dogs of the race German Shepherd. It was used 26 male dogs, with 1 to 6 years of age, of the race German Shepherd, clinically healthy and belonging the Military Police of Rio de Janeiro. Two rows of simultaneous collections of blood and urine samples were performed with a fifteen-days interval. Just of three animals it was not possible to do the second obtaining of samples. Urine urea (Uu), serum urea (Su), urine creatinine (Ucr), serum creatinine (Scr) and of the relationships urine urea/serum urea (Uu/Su) and urine creatinine/serum creatinine (Ucr/Scr) were rated, showing the following figures: 2,4 to $19,3(7,04 \pm 2,945) \mathrm{g} / \mathrm{dl} ; 18$ to $74(41,40 \pm 11,26) \mathrm{mg} / \mathrm{dl} ; 91$ to $603(262,63 \pm 112,77)$ $\mathrm{mg} / \mathrm{dl} ; 0,45$ to $1,70(0,92 \pm 0.28) \mathrm{mg} / \mathrm{dl} ; 56,76$ to $348,48(169,86 \pm 68,50)$ and 70 to $945(326,27 \pm 193,15)$. The urinalysis, in relation to the physical exam, it revealed that the color varied from the light yellow to the golden yellow, odor was 
considered thoroughly characteristic, the aspect varied of transparent the cloudy, the consistence was flowing, the specific gravity oscillated among 1.016 to $1.080(1.048 \pm 46)$ and the pH stayed among 5.0 to $8.0(5.9 \pm 0.9)$. most of the urine samples $(90 \%)$ it presented $\mathrm{pH}$ same or inferior to 7.0 . On the other hand, the chemical exam proteinuria were observed $(20,24 \%)$, bilirrubinuria $(4,08 \%)$ and occult blood $(12,24 \%)$. the sediment examination $(400 \mathrm{X})$ revealed the presence of crystalluria (calcium oxalate: $4,08 \%$, calcium phosphate: $8,16 \%$, triple phosphate: $8,16 \%$, amorphous urates: $6,12 \%)$; casts $(4,08 \%)$ (granular casts: rare to 1 for field), pyuria (100\%) (piocitos: 1 to 20 for field), hematuria (100\%) (erythrocytes: 1 to 7 for field), squamous epithelial cells (100\%) ( 1 to 8 for field) and spermaturia (48,97\%).

Keywors: dog; urea; creatinine; urinalysis.

\section{Referências bibliográficas}

BUSH, B. M. Interpretation of laboratory results for small animal clinicians. London : Blackwell Scientific Publications, $1991.515 \mathrm{p}$.

CHEW, D. J., DiBARTOLA, S. P. Manual of small animal nephrology and urology. New York : Churchill Livingstone, 1986. $340 \mathrm{p}$.

COLES, E. H. Patologia Clínica Veterinária. 3. ed. São Paulo : Manole, 1984. $566 \mathrm{p}$.

DUNCAN, J. R., PRASSE, K. W. Patologia Clínica Veterinária. Rio de Janeiro : Guanabara Koogan, 1982. 217 p.

DUNCAN, J. R.; PRASSE, K. W., MOHOFFREY, E. A. Veterinary laboratory medicine: clinical pathology. lowa: $3^{\text {rd }}$ ed., lowa State University, 1994. $300 \mathrm{p}$

EDWARDS, D. J.; BROWNLOW, M. A; HUTGHINS, D. R. Indices of renal function: reference values in normal horses. Aust. Vet. J., v. 66, p. 60-63, 1989.

ETTINGER, S. J., FELDMAN, E. C. Textbook of Veterinary Internal Medicine. Philadelphia: 4. ed., Saunders, 1995, 2 v. $2146 \mathrm{p}$.

FINCO, D. R., BARSANTI, J. A. Mechanism of urinary creatinine excretion by the cat. Am. J. Vet. Res., v. 43, p. 2207-2209, 1982.

GOLDSTON, R. T.; WILKES, R. D.; SEYBOLD, I. M. Evaluation of renal function: blood urea nitrogen and creatinine determinations. Vet. Med. Small Anim. Clin., v. 4, p. 157160,1981

GROSSMAN, B. S.; BROBST, D. F. ; KRAMER, J. W.; BAYLY, W. M. , REED, S. M. Urinary indices for differentiation of prerenal azotemia and renal azotemia in horses. J. Am Vet. Med. Assoc., v. 180, p. 284-288, 1982.

JERGENS, A. E.; McCAW, D. L., HEWETT, J. E. Effects of collection time and food consumption on urine protein / creatinine ratio in the dog. Am. J. Vet. Res., v. 48, p. 11061109, 1987.

KANEKO, J. J. Clinical Biochemistry of Domestic Animals. $3^{\text {rd }}$ ed. New York : Academic Press, 1980. 831 p.

KIRK, R. W. Atualização Terapêutica Veterinária. São Paulo : Manole, 1988,2 v. 1688 p.
LING, G. V. Lower urinary tract diseases of dogs and cats. Philadelphia : Mosby, 1995. 235 p.

MATOS, M. S., MATOS, P. F. Laboratório clínico médico veterinário. São Paulo : Atheneu, 1988. 238 p.

MEDWAY, W.; PRIER, J. E., WILKINSON, J. S. Patologia Clínica Veterinária. México : Uteha, 1973. $532 \mathrm{p}$.

MEYER, D. J., COLES, E. H., RICH, L. J. Veterinary laboratory medicine. Philadelphia : Saunders, 1992. 350 p.

NAVARRO-GARCIA, C. E. K. Manual de urinálise clínica. São Paulo : Varela, 1996. 95 p.

O'BRIEN, J. P., O'GRADY, M., LUMSDEN, J. H., HOLMBERG, D. L., SHEN, H., WEILER, J. E., HORN, R. D., MIRSALINI, S. M., JULIAN, R. J. Clinical pathologic profiles of dogs and turkeys with congestive heart failure, either noninduced or induced by rapid ventricular pacing, an turkeys with furazolidone toxicosis. T. Vet. Res., v. 54, p. 60-68, 1993.

O'CONNELL, J. M. R., ROMEO, J. A., MUDGE, G. H. Renal tubular secretion of creatinine in the dog. Am. J. Physiol., v. 203, p. 985-990, 1962.

OSBORNE, C. O., FINCO, D. R. Canine and feline nephrology and urology. Philadelphia : Williams \& Wilkins, 1995: 960 p.

SMITH, E. L., HILL, R. L., LEHMAN, I .B., LEFKOWITZ, R. J., HANDLER P., WHITE, A. Bioquímica: aspectos gerais. 7. ed. Rio de Janeiro : Guanabara Koogan, 1985. 785 p.

SODIKOFF, C. Laboratory profiles of small animal diseases. Santa Barbara : American Veterinary Publication, 1981. 215 p.

SWANSON, R. E., HAKIM, A. A. Stop-flow analysis of creatinine excretion in the dog. Am. J. Physiol., v. 203, p. 980-984, 1962.

VIEIRA, S. Introdução à bioestatística. 6. ed. Rio de Janeiro : Campus, 1989. 294 p.

WATSON, A. D. J., CHURCH, D. B., FAIRBURN, A. J Postprandial changes in plasma urea and creatinine concentration in dogs. Am. J. Vet. Res., v. 42, p. 1878-1880, 1981.

WILLARD, M. D., TVEDTEN, H., TURNWALD, G. H. Small animal clinical diagnosis by laboratory methods. 2. ed. Philadelphia : Saunders, 1994. 377 p. 